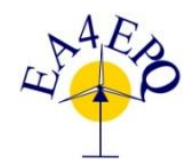

International Conference on Renewable Energies and Power Quality (ICREPQ'13)

Bilbao (Spain), 20th to 22th March, 2013

Renewable Eenergy and Power Qualily. Tournal (RE\&PQJ)

ISSN 2172-038 X, No.11, March 2013

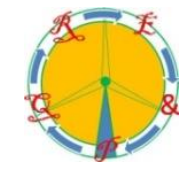

\title{
Feasibility of Residential Wind Energy Generation in Puerto Rico
}

\author{
R. Darbali Zamora, Student Member, IEEE and Dr. A. J. Díaz Castillo Senior Member, IEEE \\ Department of Electrical and Computer Engineering \\ University of Puerto Rico \\ 00681-9000 Mayagüez \\ E-mail: rachid.darbali@upr.edu, andres.diaz@ece.uprm.edu
}

\begin{abstract}
In Puerto Rico the rising cost of electrical energy from fossil fuels has created the necessity to use alternative energy sources for electricity generation. Wind energy, an accessible and clean source of energy, can help Puerto Rico achieve energy independence. Due to high population density, urban spread, lack of land use planning and the ever-growing concerns for the safety of flora and fauna, large-scale commercial wind generation has been met with increasing public opposition. Residential wind energy is most commonly used by homes and private land owners, making it less controversial. In this study we analyze recently obtained wind speed data from CariCOOS to help select a small residential wind turbine. An economical analysis of a residential wind turbine project is presented using the estimated energy produced.
\end{abstract}

Index Terms - wind energy, small wind, residential wind energy generation, weibull distribution, economical analysis

\section{Introduction}

$\mathrm{T}$ he increasing price of foreign fossil fuels causes an economic burden in Puerto Rico that promotes the use of endogenous renewable energy resources [1]. Reducing pollution and greenhouse gas emissions are additional incentives to implement renewable energy. Puerto Rico is a mountainous island with a total area of $9,104 \mathrm{~km}^{2}$ and a population of approximately 3,979,000 [U.S. Census Bureau]. The annual average energy consumption for residential customers in the United States is $11,000 \mathrm{kWh}$ at a rate of $9 \not$ per $\mathrm{kWh}$ [Department of Energy, 2008]. The average price of residential electricity in Puerto Rico as of 2010 was between 18-20ф [J. Maduro, Personal Communication, February 8, 2010] and as of 2012 has increased to $28 \notin$ per $\mathrm{kWh}$ [AEE, March, 1, 2012]. Puerto Rico possesses strong enough winds to utilize existing technology designed to harness wind to generate electricity [2]. Wind turbines use blades that are lifted and rotated when hit by strong winds. The blades spin a shaft connected to an electrical generator that converts the wind's kinetic energy into mechanical energy used to produce electricity. Small residential wind turbines, mostly used to power homes, farms and small businesses, are able to generate electricity in an environmentally friendly manner by harnessing the power of wind. A typical residential wind turbine has a hub height that can range from $30 \mathrm{ft}$ to $130 \mathrm{ft}$ tall. In this article we show that using compact wind turbines in residential and small commercial applications is economically viable with the wind resources available in Puerto Rico. This analysis considers the positive effect of tax incentives and investment rebates available to individuals who decide to invest in renewable energy. This article is organized in the following manner: section 2 presents the available wind energy resources for selected sites in the northern, eastern and southern coast of Puerto Rico. We present and analyze wind data available from CariCOOS. Section 3 shows the wind turbine we selected and presents the method used to match the wind resource with the selected wind turbine as well as an estimate of the amount of electricity generated at each site. Section 4 introduces the Net Present Value (NPV), the Simple Payback (SPB) and the Internal Rate of Return (IRR) as well as an economical comparison of each site. Finally, section 5 presents our conclusions.

\section{Wind Characteristics In Puerto Rico}

Wind is the movement of air produced as our planet attempts to reach thermal equilibrium due to the change in surface temperature caused by uneven absorption of solar radiation. Winds in Puerto Rico are a result of trade winds that originate from the east. Figure 1 illustrates the map of Puerto Rico and the sites under study.

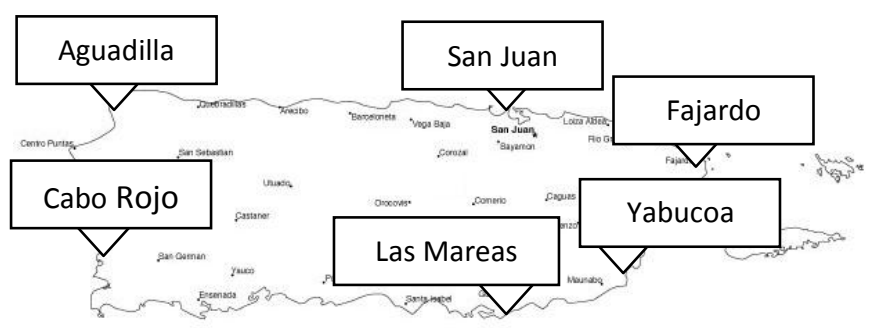

Fig. 1: Map of Puerto Rico

In order to identify which locations have favorable wind characteristics, hourly wind speed data was obtained from the Caribbean Coastal Ocean Observation System 
(CariCOOS). CariCOOS forms part of the Caribbean Regional Association for Integrated Coastal Ocean Observing (CaRA). This effort is funded by the NOAA IOOS office. All studied sites are located next to the ocean in the Municipalities of: Aguadilla, Cabo Rojo, Las Mareas, Yabucoa, Fajardo, and San Juan. Table I shows the coordinates for each site and the height at which the wind data was measured. We analyzed one year of data, from January 26, 2010 at noon (12:00) to January 26, 2011 at 11:00 am.

TABLE I: Measurement Site Description

\begin{tabular}{|c|c|c|c|}
\hline Location & Latitude & Longitude & Height $(\mathbf{m})$ \\
\hline Aguadilla & 18.43 & -67.16 & 4.3 \\
\hline Cabo Rojo & 18.10 & -67.19 & 16.2 \\
\hline Fajardo & 18.29 & -65.63 & 13.4 \\
\hline Las Mareas & 17.93 & -66.16 & 8.8 \\
\hline San Juan & 18.46 & -66.13 & 14.3 \\
\hline Yabucoa & 18.05 & -65.83 & 9.8 \\
\hline
\end{tabular}

\section{A. WIND DIRECTION IN PUERTO RICO}

To harness wind power more efficiently, wind turbines should be positioned to receive the wind directly. Puerto Rico is mainly exposed to winds that travel from east to west of the island [3]. Figures 2 through 4 illustrate wind rose data that describe wind directions in selected locations of Las Mareas, Fajardo and San Juan.

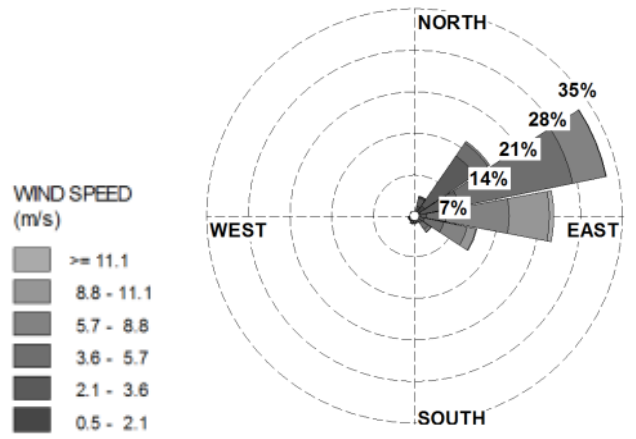

Fig. 2: Wind Direction Frequency Distribution, Las Mareas

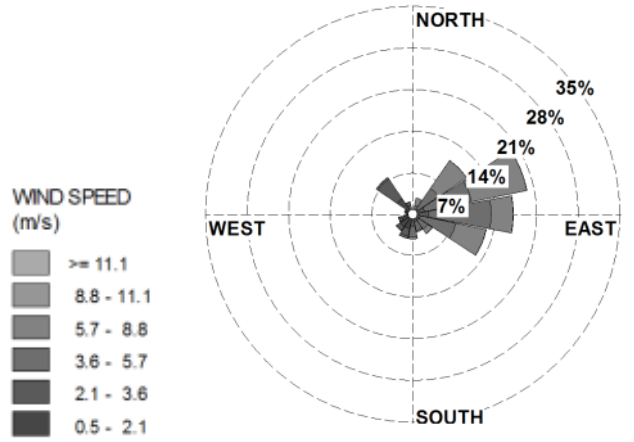

Fig. 3: Wind Direction Frequency Distribution, Fajardo

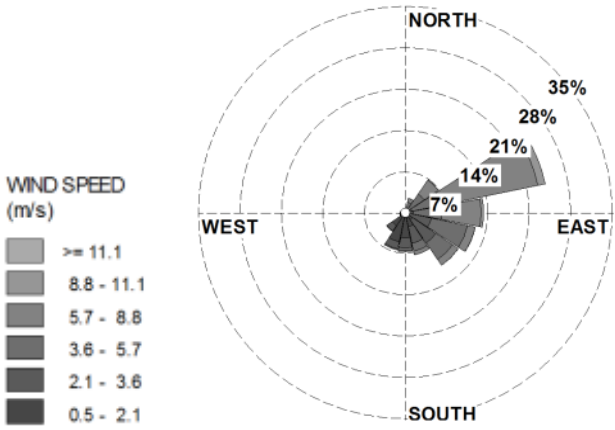

Fig. 4: Wind Direction Frequency Distribution, San Juan

Winds in Las Mareas (southern Puerto Rico) predominantly travel from the east and northeast towards the west. This location exhibits the strongest wind speeds compared to other selected locations. Fajardo (eastern Puerto Rico) exhibits adequate wind speeds that travel from the east and northeast towards the southwest. Winds in San Juan (northern Puerto Rico) were measured in a small infrastructure above water that is used to guide ships. These winds travel from the northeast towards the southwest of Puerto Rico.

\section{B. WIND SPEED DISTRIBUTION IN PUERTO RICO}

Puerto Rico is subject to three different kinds of winds: sea breezes, land breezes and the trade winds that blow from the east towards the west throughout most of the year. This means that eastern Puerto Rico receives winds without being slowed down by the island's mountainous geography. Due to their proximity to the ocean, the winds of the selected sites are mainly produced by both trade winds and sea breezes. Before implementing wind turbine technology, wind speed distribution must first be analyzed. To estimate the power generated in each location, a histogram of available winds is constructed. The wind speed heights are adjusted using the power law equation to fit the wind turbines' hub height [4]. This equation is shown in expression (1).

$$
v_{2} / v_{1}=\left(h_{2} / h_{1}\right)^{\alpha}
$$

Expression (1) shows the relationship between height and wind speed, where $v_{2}$ is the wind speed at the desired height $h_{2}, v_{l}$ is the wind speed measured at a known height $h_{l}$, and $\alpha$ is the wind shear coefficient. The wind shear exponent varies with pressure, temperature and time of day. A commonly used value is one-seventh (1/7). The collected wind speed data has been adjusted to a height of 18 meters to satisfy the selected wind turbines' hub height. A histogram to obtain each site's frequency distribution is developed by assorting hourly wind speed occurrences. These histograms are paired with the power curve of a selected wind turbine to estimate the potential energy generated in each site and is illustrated in figures 5 though 7 . 


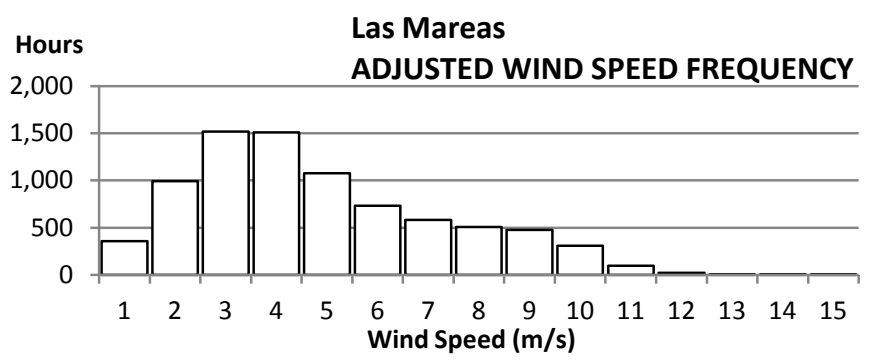

Fig. 5: Las Mareas, Wind Speed Frequency

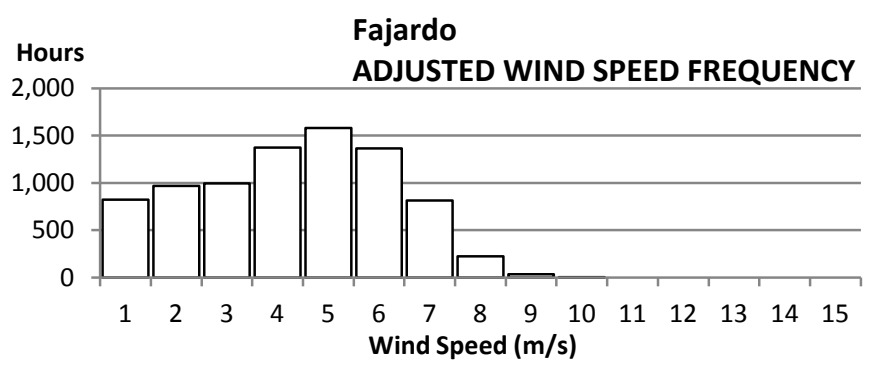

Fig. 6: Fajardo, Wind Speed Frequency

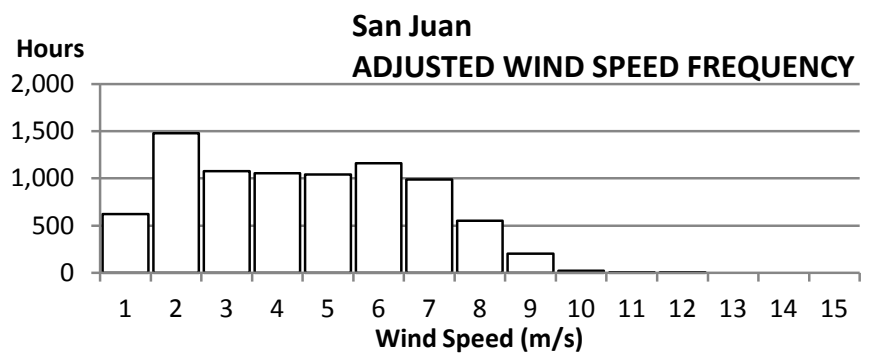

Fig. 7: San Juan Wind Speed Frequency

\section{WEIBULL PROBABILITY DENSITY FUNCTION}

The Weibull distribution is a probabilistic function that helps describe the likelihood of certain events. Due to its accuracy, it is frequently used to identify the viability of wind turbine projects by predicting the variations of wind speeds. The equation for the Weibull Probability Function is shown in expression (2).

$$
f(v)=\frac{k}{\lambda}\left(\frac{v}{\lambda}\right)^{k-1} e^{-\left(\frac{v}{\lambda}\right)^{k}}
$$

The Weibull probability density function is defined by two parameters. The variable $k$ is known as the shape factor, reflects the shape of the Weibull distribution. The variable $\lambda$ is known as the scale factor and defines where the majority of the distribution lies as well as how stretched out the distribution will be. The variable $v$ is a vector of the measured wind speeds at the desired location [5]. Using the Matlab function wblfit $(x)$, which returns the maximum likelihood estimates for the Weibull probability density function and our collected wind speed data, it is possible to obtain the Weibull parameters $k$ and $\lambda$ needed for the analysis [6]. Table II shows the calculated parameters $k$ and $\lambda$ given by the Matlab function $\operatorname{wblfit}(x)$ for all the selected areas.

TABLE II: Weibull Probability Distribution Parameters

\begin{tabular}{|c|c|c|}
\hline Location & Parameter: $\boldsymbol{\lambda}$ & Parameter: $\mathbf{k}$ \\
\hline Aguadilla & 3.48846 & 1.19145 \\
\hline Cabo Rojo & 2.3436 & 2.0084 \\
\hline Fajardo & 4.7458 & 2.2770 \\
\hline Las Mareas & 5.4298 & 2.0592 \\
\hline San Juan & 4.9890 & 2.1095 \\
\hline Yabucoa & 4.6563 & 2.0978 \\
\hline
\end{tabular}

Using these parameters we are able to use the Matlab function $\operatorname{wblpfd}(v, \lambda, k)$, that calculates the probability density function for each of the selected measurement stations and is shown in figures 8 through 10 .

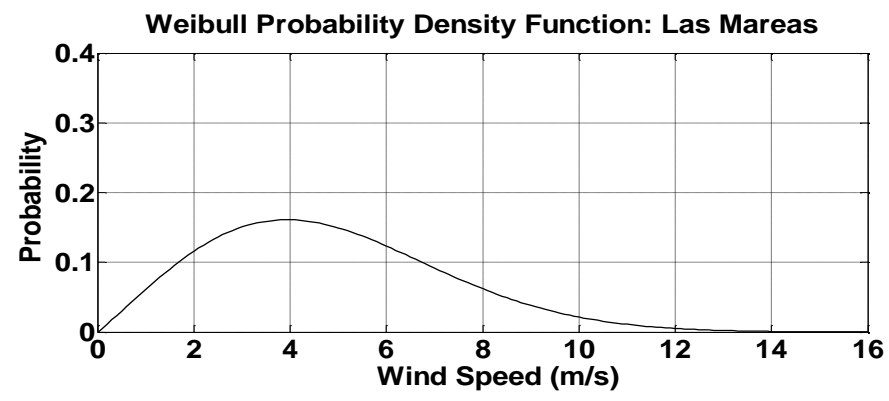

Fig. 8: Weibull Distribution in Las Mareas

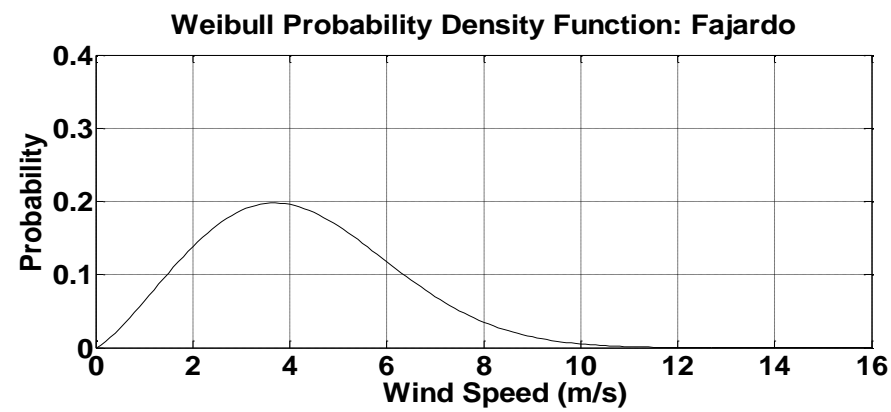

Fig. 9: Weibull Distribution in Fajardo

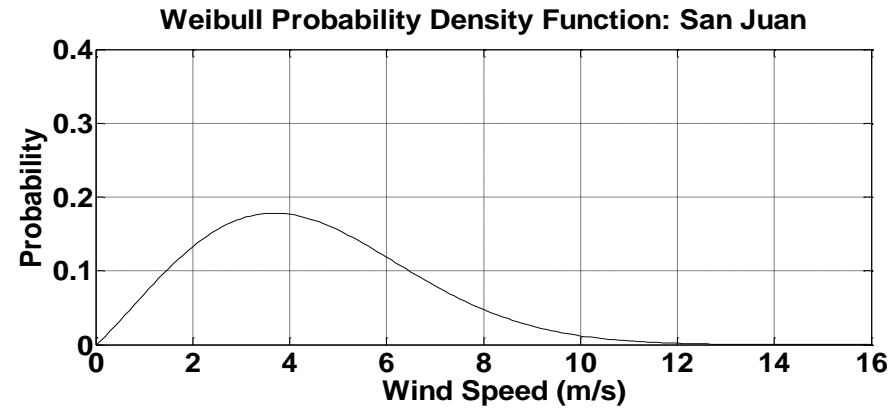

Fig. 10: Weibull Distribution in San Juan 


\section{Power Generation In Puerto Rico}

The power generated by a wind turbine can be calculated from available wind speeds using the equation shown in expression (3).

$$
P=\frac{1}{2} \rho v^{3} A
$$

In this equation $\rho$ is air density in $\mathrm{kg} / \mathrm{m}^{3}, v$ is wind speed in $\mathrm{m} / \mathrm{s}$ and $A$ is sweep area in $\mathrm{m}^{2}$. When calculations are made, a $10 \%$ inaccuracy in wind speeds can produce a $33 \%$ miscalculation in actual power generation [6]. To avoid this imprecision, energy production is estimated by matching the obtained wind speed frequency with a wind turbines power curve that can accommodate wind speeds in the desired regions [7]. A power curve is a characteristic graph that represents the turbine power output at different wind speed values and is normally provided by the turbine's manufacturer to help approximate power generation. The residential wind turbine model selected for this analysis is the Bornay Inclin 6000 , generating $6 \mathrm{~kW}$ at a rated speed of $12 \mathrm{~m} / \mathrm{s}$. The lifetime of the selected wind turbine is 20 years. Figure 11 shows the power curve of the selected wind turbine model.

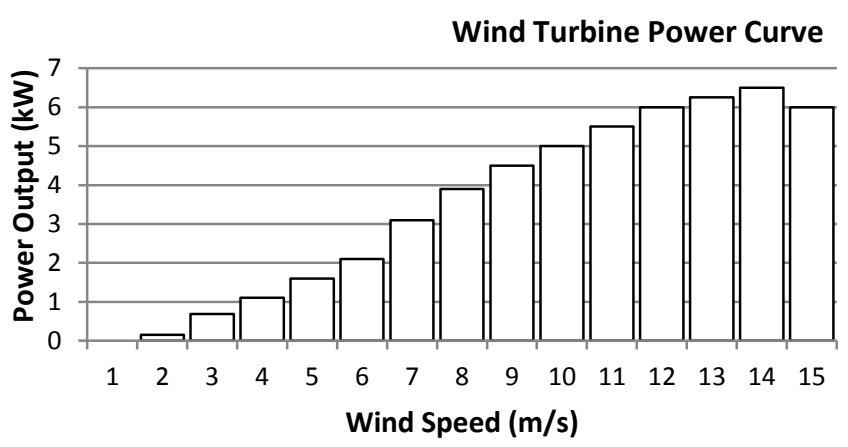

Fig. 11: Inclin 6000 Wind Turbine Power Curve

To determine what sites are prospective locations for wind energy generation, the annual energy produced by a Bornay Inclin 6000 was estimated. Figure 12 shows the results for the annual energy generation.

Annual Energy Generated

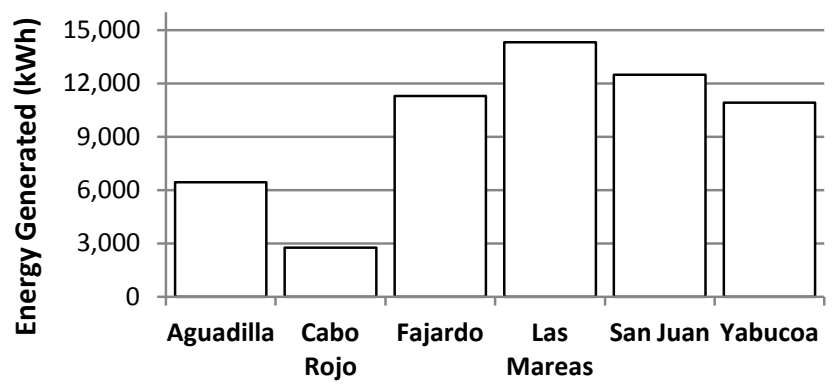

Fig. 12: Annual Energy Generated in Puerto Rico
Table III shows the yearly energy generated in Puerto Rico for an entire year using the Bornay Inclin 6000 wind turbine model.

TABLE III: Annual Energy Generated in Puerto Rico

\begin{tabular}{|c|c|}
\hline Location & Energy Generated (kWh) \\
\hline Aguadilla & 6,444 \\
\hline Cabo Rojo & 2,760 \\
\hline Fajardo & 11,284 \\
\hline Las Mareas & 14,316 \\
\hline San Juan & 12,481 \\
\hline Yabucoa & 10,914 \\
\hline
\end{tabular}

\section{Economical Analysis}

To fully understand if a residential wind turbine project will be a successful investment, an economical analysis is performed. An important aspect is the price of energy per $\mathrm{kWh}$. This cost varies through the years and may escalate; this is known as the utility escalation. To obtain the utility escalation we examine its behavior using historical data [AEE]. Figure 13 shows how the cost of energy has increased during the past 10 years.

Average Cost of Energy - Residential (\$/kWh)

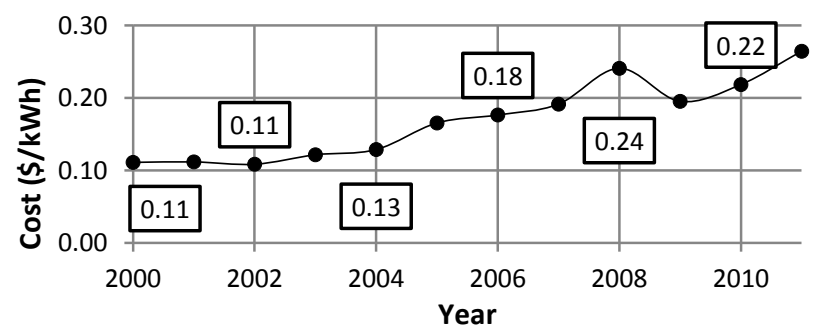

Fig. 13: Average Cost of Energy in the Last Decade

These results show that the price of energy escalates approximately $2 \phi$ per $\mathrm{kWh}$ each year. This analysis assumes an initial value of $28 \notin$ per $\mathrm{kWh}$ to obtain the initial annual price of energy generated. Figure 14 shows the price of the energy generated in Puerto Rico for an entire year using the Bornay Inclin 6000 wind turbine model.

Estimated Value of Energy

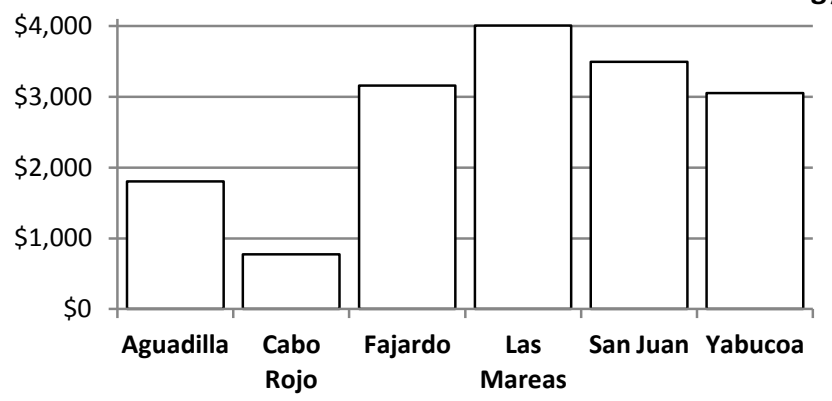

Fig. 14: Price of Energy Produced in Puerto Rico 
Table IV shows the numerical results of the price of the energy generated in Puerto Rico for an entire year.

TABLE IV: Price of Energy Produced in Puerto Rico

\begin{tabular}{|c|c|}
\hline Location & Price of Energy \\
\hline Aguadilla & $\$ 1,804$ \\
\hline Cabo Rojo & $\$ 773$ \\
\hline Fajardo & $\$ 3,160$ \\
\hline Las Mareas & $\$ 4,008$ \\
\hline San Juan & $\$ 3,495$ \\
\hline Yabucoa & $\$ 3,056$ \\
\hline
\end{tabular}

The capital cost of the project is composed of the unit price of the wind turbine, an 18 meter tower, shipping, inverter, installation, and miscellaneous costs. The economic analysis takes into account the availability of tax incentives and investment rebates available for investments in residential scale renewable energy projects [8]. Table $\mathrm{V}$ summarizes the approximate cost of a small-scale residential wind turbine project.

TABLE V: Estimated Wind Turbine Costs and Incentives

\begin{tabular}{|c|c|c|}
\hline \multicolumn{3}{|c|}{ General Case Scenario } \\
\hline Capacity & 6 & $\mathrm{~kW}$ \\
\hline Project Lifetime & 20 & yrs \\
\hline Electrical Retail Rate & 28 & $\phi / \mathrm{kWh}$ \\
\hline Utility Escalation & 2 & $\phi / \mathrm{kWh}$ per year \\
\hline \multicolumn{3}{|c|}{ Capital Cost } \\
\hline Inclin 6000 Wind Turbine & $\$ 15,000.00$ & - \\
\hline Equipment Cost & $\$ 22,600.00$ & - \\
\hline Installation Cost & $\$ \quad 5,000.00$ & - \\
\hline Total Cost & $\$ 42,600.00$ & - \\
\hline \multicolumn{3}{|c|}{ Operation and Maintenance } \\
\hline Annual O\&M & $\$ \quad 143.16$ & $\$ 0.01$ per $\mathrm{kWh}$ \\
\hline Annual Insurance & $\$ \quad 170.00$ & $\begin{array}{l}1 \% \text { of Capital } \\
\text { Cost }\end{array}$ \\
\hline Inflation Rate & $3 \%$ & [9] \\
\hline \multicolumn{3}{|c|}{ Economic Details } \\
\hline Grant percentage & $60 \%$ & - \\
\hline Grant $60 \%$ & $\$ 25,560.00$ & - \\
\hline Rate & $10 \%$ & - \\
\hline
\end{tabular}

Using these conditions it is possible to construct the cumulative cash flow for all the selected locations. A cash flow is the study of money that is financially invested during a specific period of time. A positive outcome illustrates that the project is generating profit. Consequently, a negative outcome implies that the system is generating losses. The cumulative cash flow helps identify the total net cash flow through the end of each period. The location with the most profit can be identified by the cash flow that starts generating profit in the least amount of time. Figures 15 through 17 illustrate the cumulative cash flow for the selected locations of Las Mareas, Fajardo and San Juan.

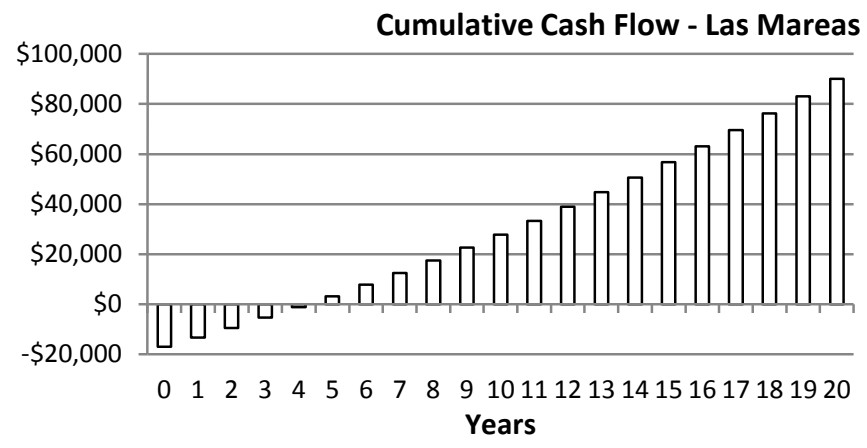

Fig. 15: Cash Flow, Las Mareas

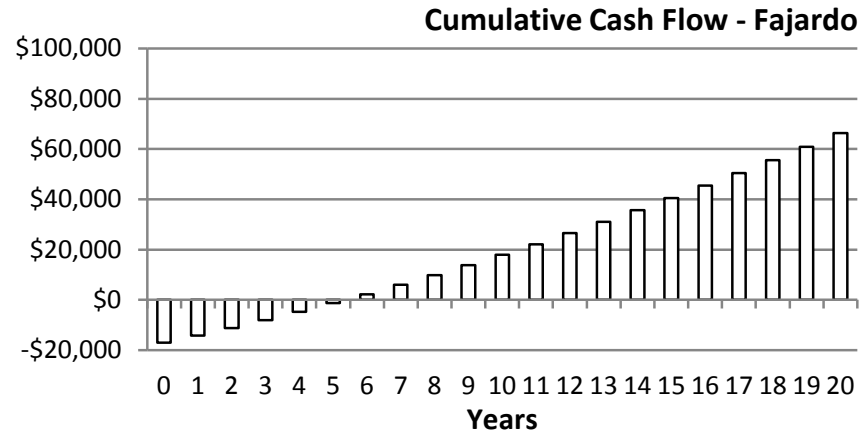

Fig. 16: Cash Flow, Fajardo

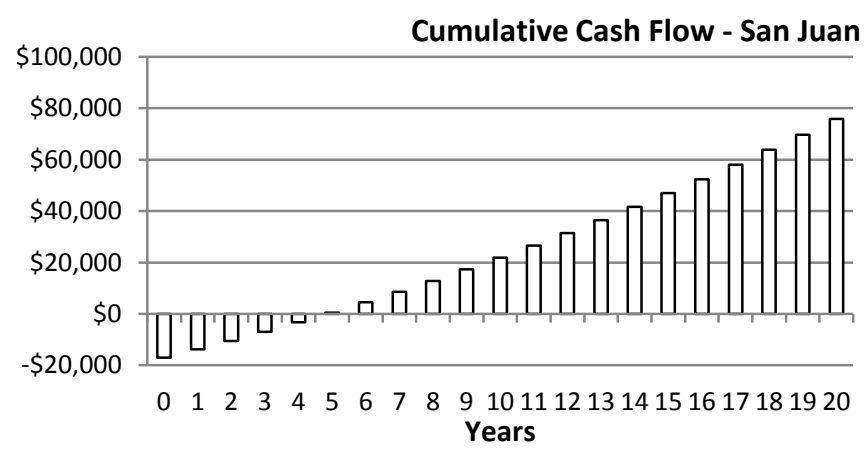

Fig. 17: Cash Flow, San Juan

The cash flow for Las Mareas shows that the investment starts generating earnings in year 5 . In the same manner the cash flow for Fajardo also indicates the investment becomes profitable in 6 years. It takes 5 years for San Juan to start generating income. To avoid any negative economical consequences and determine that a project is cost-effective, the NPV, SPB and IRR calculations are made to help provide a glimpse of the value of an investment on a given date [10]. The NPV is the process of taking an investment and projecting its future net income. It represents the 
amount of money an investment is worth in the present. The equation that represents the NPV is shown in expression (4).

$$
N P V=\sum_{n=0}^{N} \frac{C_{n}}{(1+i)^{n}}
$$

The variable $n$ represents the cash flow period, while $C_{n}$ is the cash flow and $i$ is the rate of return [11]. Figure 18 shows the results obtained by calculating the NPV in all locations.

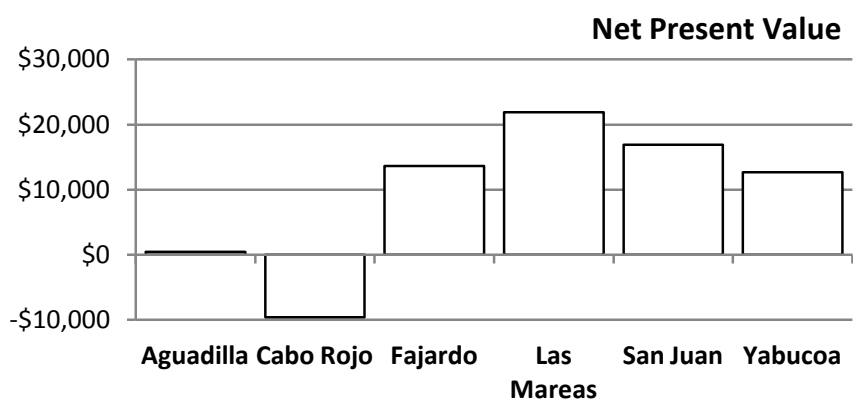

Fig. 18: Net Present Value

The SPB is the amount of time it will take to recover an initial investment. The IRR is a rate of return on an investment. Numerical results for the calculated NPV, the IRR and for the SPB are summarized in Table VI.

TABLE VI: Economical Analysis Results

\begin{tabular}{|c|c|c|c|}
\hline Location & NPV & IRR & SPB \\
\hline Aguadilla & $\$ 462.32$ & $10 \%$ & 10.9 \\
\hline Cabo Rojo & $-\$ 9,583.56$ & $0 \%$ & 29.7 \\
\hline Fajardo & $\$ 13,660.49$ & $20 \%$ & 5.9 \\
\hline Las Mareas & $\$ 21,928.43$ & $25 \%$ & 4.6 \\
\hline San Juan & $\$ 16,924.58$ & $22 \%$ & 5.3 \\
\hline Yabucoa & $\$ 12,651.53$ & $19 \%$ & 6.1 \\
\hline
\end{tabular}

\section{Conclusion}

It is apparent that the studied locations to the west side of Puerto Rico do not possess enough strength for a profitable outcome. However, results show that there are wind speeds for a feasible residential wind turbine project located closer to the east side of Puerto Rico. These locations are directly exposed to trade winds, sea breezes and consequently produce greater power output. Creating a wind rose helps illustrate that any wind turbine placed in these sites should be oriented facing the northeast. The Weibull probability density function provides an idea of how frequently strong winds will occur. The Matlab Weibull function is a quick and easy way to obtain the necessary parameters needed to generate these distributions. As we move farther from locations in the west and closer to locations in the east, the likelihood of receiving low wind speeds decreases while stronger wind speeds become more probable. In the case scenario, the Bornay Inclin 6000 model takes advantage of the low wind speeds and is more cost-effective compared to other residential wind turbines that are on the market. This research is the stepping stone in developing low-cost drivers for residential wind turbines, one of the graduate level research areas of the power electronics program at University of Puerto Rico. This will also form part of an undergraduate curriculum review that focuses on developing proposed DOE-UMN-UPR laboratories.

\section{Acknowledgements}

The authors gratefully acknowledge the contributions made by Dr. Agustín Irizarry-Rivera, the Caribbean Coastal Ocean Observation System (CariCOOS), University of Minnesota (UMN), and University of Puerto Rico at Mayagüez (UPRM), as well as the financial support of the Department of Energy (DOE) through grant number A000211546.

\section{References}

[1]. H.R. Zamot, E. O'Neill-Carrillo and A. Irizarry-Rivera, "Analysis of Wind Projects Considering Public Perception and Environmental Impact," Power Symposium, 2005. Proceedings of the 37th Annual North American, Oct 23 - 25 2005, pp. $591-596$.

[2]. A. Irizarry, J. A. Colucci-Rios and E. O’Neill, “Achievable Renewable Energy Targets for Puerto Rico's Energy Standard: Final Report, Puerto Rico's Energy Affairs Administration", Oct. 2007 - Nov. 2008.

[3]. K. Altaii and R.N Farrugia, "Wind characteristics on the Caribbean island of Puerto Rico," Renewable Energy, Sept. 2003, Vol. 28, pp. 1701 - 1710.

[4]. T. Burton, D. Sharpe and N. Jenckins, E. Bossanyi, "Wind Energy Handbook," Second Edition, John Wiley \& Sons, June 21, 2011.

[5]. R. Wang; W. Li; and B. Bagen, "Development of Wind Speed Forecasting Model Based on the Weibull Probability Distribution," Computer Distributed Control and Intelligent Environmental Monitoring (CDCIEM), 2011 International Conference on, pp. 2062 - 2065, Feb 2011 19-20

[6]. C. Ramos-Robles and A. Irizarry-Rivera, "Economical Effects of the Weibull Parameter Estimation on Wind Energy Projects," Power Symposium, 2005. Proceedings of the 37th Annual North American, pp. 597 - 602, Oct. 23-25 2005.

[7]. P. Gipe, "Wind Power for Home and Business: Renewable Energy for the 1990s and Beyond," Vermont: Chelsea Green Publishing Company, 1993.

[8]. E. Arosemena Munoz, "Green Energy Fund Rebates Regulation, Government of Puerto Rico: Puerto Rico Energy Affairs Administration", June 2011.

[9]. P. Gipe, "Wind Power: Renewable Energy for Home, Farm, and Business," Vermont: Chelsea Green Publishing Company, 2004.

[10]. M. Rasheduzzaman, E. Stahlman, and B.H. Chowdhury, "Investment payback calculator for distributed generation sources," North American Power Symposium (NAPS), 2011, Aug. 4 - 6 2011, pp. 1 - 7.

[11]. C. A. Magni, "Average Internal Rate of Return and Investment Decisions: A New Perspective. (Internal Rate of Return).” Engineering Economist. April-June 2011, pp 150. 